\title{
COMPARATIVE EFFICACY OF PHENYTOIN VERSUS LIDOCAINE IN THE MANAGEMENT OF INTRACTABLE SEIZURE IN NEONATE
}

\author{
AL BAQUI SA ${ }^{1}$, KHAN TH$^{2}$, MOLLAH AH ${ }^{3}$, BANERJEE $\mathrm{M}^{4}$, RAHMAN $\mathrm{M}^{5}, \mathrm{CHOWDHURY} \mathrm{AS}^{6}$, ISLAM $^{7}$
}

\begin{abstract}
Background : Intractable neonatal seizure are common acute medical emergency in neonatal period than at any other period of life. In our daily practice treatment of intractable neonatal seizures still relies primarily on phenytoin, despite an estimated efficacy of less than $50 \%$ and concern over neurodegenerative side effects. Several studies indicate value for lidocaine as an anticonvulsant in the treatment of intractable neonatal seizure.
\end{abstract}

Aim : The objective of this study was to compare the efficacy of Phenytoin with Lidocaine in the management of intractable seizure in neonate.

Methodology : A Randomized control trial was carried out in the Department of Neonatology, Dhaka Medical College Hospital (DMCH), Dhaka between July 2013 to June 2014. A total of 78 newborn with neonatal seizure. admitted in SCABU \& not responding to total doses of Inj. Phenobarbital $(40 \mathrm{mg} / \mathrm{kg})$ were included in the study and were randomly assigned to either Inj. Lidocaine (Group A=39) or to Inj. Phenytoin (Group B=39). The main outcome variables were control of seizure, adverse effects, time of cessation of seizure.

Results : The study demonstrated that intractable seizure of 24 neonates (75\%) were controlled with Inj. Lidocaine and intractable seizure of 20 neonates (57.1\%) were controlled with Inj. Phenytoin(P-Value 0.124). Adverse effects of drugs such as apnea, bradycardia, drowsiness and lethargy were observed in 4 patients (12.5\%) of Lidocaine group (Group A) and 10 (28.6\%) of Phenytoin group $(G r o u p=B)(P$-Value 0.106). Time required for cessation of intractable seizures were nearly similar in both groups. In group A 75\% of patients responded within 24 hours and in group $B 71 \%$ patients responded in same duration(P-Value 0.931). Length of hospital stay was less in phenytoin group compare to lidocaine group(P-Value 0.352). None of the following results were statistically significant.

Conclusion : The study concluded that Inj. Lidocaine is similar to Inj. Phenytoin in controlling intractable neonatal seizure.

Keywords: Efficacy, Phenytoin, Lidocaine, Intractable seizure.

J Dhaka Med Coll. 2016; 25(2) : 94-99

\section{Introduction:}

A seizure is defined clinically as a paroxysmal alteration in neurological function i.e., motor, behavioral and/or autonomic function. ${ }^{1}$ The prevalence of seizure is 1-3/1000 live births in term and 10-15/1000 in preterm deliveries. ${ }^{2}$ The common cause of neonatal seizures arehypoxic ischemic encephalopathy (HIE), Metabolic causes (hypoglycaemia, hypocalaemia, hypomagnesaemia, etc), Infection (Meningitis, viral encephalitis etc), intracranial haemorrhage, Cerebral infarcts, Developmental brain defects, drug withdrawal, drug toxicity. ${ }^{1-3}$

Intractable seizure are defined when seizure events don't respond to first line treatment of an intravenous bolus of injection Phenobarbital $(20 \mathrm{mg} / \mathrm{kg})$ and up to 2 loading doses of $(10 \mathrm{mg} /$ $\mathrm{kg}$ ) Phenobarbital ${ }^{4}$ (maximum $40 \mathrm{mg} / \mathrm{kg}$ ). There is no available data about the prevalence of intractable seizure both globally and nationally.

1. Dr. Shah Abdullah-Al Baqui, Registrar, Department of Pediatrics, Dhaka Medical College Hospital, Dhaka

2. Dr. Md. Tafazzal Hossain Khan, Associate Professor of Neonatology, Dhaka Medical College Hospital, Dhaka

3. Dr. Md. Abid Hossain Mollah, Professor of Pediatrics,Dhaka Medical College Hospital, Dhaka

4. Dr. Manisha Banerjee, Professor of Neonatology, Dhaka Medical College Hospital, Dhaka

5. Dr. Md. Mahfuzur Rahman, SMO, Department of Pediatrics, National Medical Institute Hospital, Dhaka

6. Dr. Abu Sayeed Chowdhury, Registrar, Department of Pediatrics, Dhaka Medical College Hospital, Dhaka

7. Dr. Md. Saiful Islam, Asst. Registrar, Department of Pediatrics, Dhaka Medical College Hospital, Dhaka

Correspondence : Dr. Shah Abdullah-Al Baqui, Registrar, Department of Pediatrics, Dhaka Medical College Hospital, Dhaka

Received: 05 July 2016

Accepted: 01 September 2016 
Treatment options for neonatal seizures remain limited despite their relatively common occurrence even with introduction of several new antiepileptic medications over the past two decades. In addition there is significant variation in approach to the treatment of intractable neonatal seizure both in medication choice and in when, or whether to treat.

At present Phenobarbital and phenytoin is treatment of choice as $1^{\text {st }}$ and $2^{\text {nd }}$ line drugs in neonatal seizure. Laurel et al. ${ }^{5}$ study show the efficacy is only approximately $50 \%$ of Phenobarbital and phenytoin in neonatal seizure. Phenytoin was shown to only provide about a $10 \%$ to increase in intractable seizure control when given following Phenobarbital failure 5 . In addition phenytoin impairs myocardial function and can cause hypotension or arrhythmia in neonate. Federico et al 6 observed clinical side effects such as drowsiness, sleep troubles, hyperactivity, movement disorders in $43.6 \%$ cases treated with Inj. Phenytoin.

Lidocaine is effective drug and has been widely used in treatments of neonatal seizures without any severe side effects. It is an effective drug for second- or third-line treatment of neonatal seizures not responding to traditional anticonvulsant therapy ${ }^{7,8,9}$ Since 1955 it has been used as an anticonvulsant drugs in adults with status epilepticus. ${ }^{10}$ It has been used in neonates as an anticonvulsant since $1970 .{ }^{10}$ It may have following side effects such as drowsiness, convulsion in higher dose, respiratory depression, cardiovascular collapse, bradycardia. ${ }^{11}$

However, the efficacy of lidocaine for intractable neonatal seizure in neonates has not been adequately studied. So this study is intended to see the efficacy and side effects of lidocaine which may open a new horizon of management of intractable neonatal seizure.

\section{Methodology :}

A Randomized controlled trial carried out in the Department of Neonatology, Dhaka Medical College Hospital (DMCH), Dhaka between July 2013 to June 2014.

\section{Inclusion criteria:}

1. Neonates admitted in special care baby unit with seizures age 0-28 days. Birthweight $>2000$ gm; gestational age $>34$ weeks to $<42$ weeks.
2. Neonates not respond to $1 \mathrm{st}$ line anticonvulsant (e.g. inj. Phenobarbital) after giving a maximum dose of $40 \mathrm{mg} / \mathrm{kg} /$ day.

\section{Exclusion Criteria:}

1. Patients treated with inj. Phenytoin or lidocaine previously.

2. Known case of congenital heart disease.

The study included 78 patients with neonatal seizures. The two groups were randomly assigned to Inj. Lidocaine group $(\mathrm{n}=39)$ and Inj. Phenytoin (n-39). Patient's name and particulars were recorded in record file. Initial evaluation of the patient by history and clinical findings were recorded in the preformed data sheet.Base line investigation like $\mathrm{CBC}$, Blood grouping, Blood glucose, S.Calcium were done. Heart rate was monitored regularly. Loading dose $(2 \mathrm{mg} / \mathrm{kg})$ of inj. Lidocaine to one group and Loading dose $(30 \mathrm{mg} / \mathrm{kg})$ of inj. Fosphenytoin (Prodrug of Phenytoin) to other group were given under close cardiac monitoring not responding to total dose $(40 \mathrm{mg} / \mathrm{kg})$ of injection Phenobarbital. If seizures recur then $2^{\text {nd }}$ loading dose $(15 \mathrm{mg} / \mathrm{kg})$ of inj. Fosphenytoin were given. Maintenance were given $4 \mathrm{mg} / \mathrm{kg} /$ hour for first 12 hours then followed by $2 \mathrm{mg} /$ $\mathrm{kg} / \mathrm{hr}$ for next 12 hours in IV drip for lidocaine group and $7.5 \mathrm{mg} / \mathrm{kg} /$ day for twelve hours lives for phenytoin group. If convulsion occured during maintenance therapy of lidocaine or not responding to both lidocaine and fosphenytoin then Inj. midazolom was given in both groups. The patients were followed up regularly till death or discharge.

\section{Results :}

The present randomized controlled trial was intended to compare the outcome of two treatment modalities [inj. Lidocaine $=$ Group A] vs [Inj. Phenytoin = Group B] in intractable neonatal seizure.

The findings obtained from data analyses are documented below:

Table I shows basic demographic data of the neonates with intractable seizure. Out of 32 neonates in group A and 35 neonates in group $\mathrm{B}$, respectively, $20(62.5 \%)$ and $22(62.9 \%)$ were male and $12(37.5 \%)$ and $13(37.1 \%)$ were female. The sex distribution of neonates between group was statistically not significant. 
Table II shows status of neonatal intractable seizures. In group A and group B, respectively, age on admission after development of seizure was ?12 hours in case 17 (53.1\%) and 22 (62.9\%),
$>1224$ hours in case of $5(15.6 \%)$ and $7(20 \%),>24$ 36 hours in case of $5(15.6 \%)$ and $3(8.6 \%),>3648$ hours in case of $4(12.5 \%)$ and $2(5.7 \%)$, and $>48$ hours in case of $1(3.1 \%)$ and $1(2.9 \%)$ neonates. Statistically no variation was observed.

Table I

Basic demographic data of the neonates

\begin{tabular}{|c|c|c|c|}
\hline Parameters & $\begin{array}{c}\text { Group A } \\
\mathrm{n}=32(\%)\end{array}$ & $\begin{array}{c}\text { Group B } \\
\mathrm{n}=35(\%)\end{array}$ & $\begin{array}{l}\mathrm{P} \text { value } \\
\left.\text { ( } \chi^{2} \text { test }\right)\end{array}$ \\
\hline \multicolumn{4}{|l|}{$\overline{\operatorname{Sex}}$} \\
\hline Male & $20(62.5)$ & $22(62.9)$ & 0.976 \\
\hline Female & $12(37.5)$ & $13(37.1)$ & \\
\hline \multicolumn{4}{|l|}{ Gestational age (weeks) } \\
\hline Premature $(<37)$ & $3(9.4)$ & $3(8.6)$ & 0.908 \\
\hline Fullterm (37 40) & $29(90.6)$ & $32(91.4)$ & \\
\hline \multicolumn{4}{|l|}{ Birth weight (g) } \\
\hline $2000<2500$ & $5(15.6)$ & $5(14.3)$ & 0.878 \\
\hline 25004000 & $27(84.4)$ & $30(85.7)$ & \\
\hline \multicolumn{4}{|c|}{ Apgar score for neonates delivered in hospital } \\
\hline$<7$ & $5(100.0)$ & $10(100.0)$ & \\
\hline \multicolumn{4}{|c|}{ Breathing status of neonates delivered outside hospital } \\
\hline No breathing within 1 minute & $9(33.3)$ & $13(52.0)$ & 0.173 \\
\hline Breathing within 1 minute & $18(66.7)$ & $12(48.0)$ & \\
\hline
\end{tabular}

Group A : Inj. Lidocaine

Group B : Inj. Phenytoin

Table II

Age of onset and type of neonatal seizures

\begin{tabular}{|c|c|c|c|c|c|}
\hline \multirow{2}{*}{$\begin{array}{l}\text { Parameters } \\
\text { Age on admission (hour) }\end{array}$} & \multicolumn{2}{|c|}{ Group A ( $\mathrm{n}=32)$} & \multicolumn{2}{|c|}{ Group B (n=35) } & \multirow[t]{2}{*}{$\mathrm{P}$ value $\left(\chi^{2}\right.$ test $)$} \\
\hline & No. & $(\%)$ & No. & $(\%)$ & \\
\hline$<12$ & 17 & $(53.1)$ & 22 & $(62.9)$ & \\
\hline$>1224$ & 5 & $(15.6)$ & 7 & $(20.0)$ & \\
\hline$>2436$ & 5 & $(15.6)$ & 3 & $(8.6)$ & 0.734 \\
\hline$>3648$ & 4 & $(12.5)$ & 2 & $(5.7)$ & \\
\hline$>48$ & 1 & $(3.1)$ & 1 & (2.9) & \\
\hline \multicolumn{6}{|c|}{ Age at onset of intractable seizure (hour) } \\
\hline$<12$ & 17 & $(53.1)$ & 25 & $(71.4)$ & \\
\hline$>1224$ & 6 & (18.8) & 4 & (11.4) & \\
\hline$>2436$ & 5 & (15.6) & 6 & (17.1) & 0.207 \\
\hline$>3648$ & 3 & $(9.4)$ & 0 & (0) & \\
\hline$>48$ & 1 & (3.1) & 0 & (0) & \\
\hline \multicolumn{6}{|l|}{ Type of seizure } \\
\hline Subtle & 4 & (12.5) & 3 & (8.6) & \\
\hline Clonic & 2 & $(6.3)$ & 2 & (5.7) & 0.959 \\
\hline Tonic & 25 & (78.1) & 29 & (82.9) & \\
\hline Myoclonic & 1 & $(3.1)$ & 1 & $(2.9)$ & \\
\hline
\end{tabular}

Group A : Inj. Lidocaine

Group B : Inj. Phenytoin

* = Significant at $\mathrm{P}<0.05$ 
Table III shows status of treatment of neonatal seizure. In group A, seizure of $24(75 \%)$ neonates was controlled with Inj. Lidocaine and in group B, seizure of $20(57.1 \%)$ neonates was controlled with Inj. Phenytoin. Statistically no significant variation was observed between groups.
Table IV Shows treatment outcome of group A and group B neonates during hospital stay. In group A and group B, respectively, significant adverse effect of drug was observed in $4(12.5 \%)$ and $10(28.6 \%)$ neonates. Statistically no significant difference was observed.

Table III

Comparative efficacy of Inj. Phenytoin versus Inj. Lidocaine in controlling intractable neonatal seizure.

\begin{tabular}{|c|c|c|c|c|c|}
\hline \multirow[t]{2}{*}{ Parameters } & \multicolumn{2}{|c|}{ Group A (n=32) } & \multicolumn{2}{|c|}{ Group B $(n=35)$} & \multirow[t]{2}{*}{$\mathrm{P}$ value $\left(\chi^{2}\right.$ test $)$} \\
\hline & No. & $(\%)$ & No. & $(\%)$ & \\
\hline \multicolumn{6}{|l|}{ Seizure controlled } \\
\hline Yes & 24 & $(75.0)$ & 20 & $(57.1)$ & \multirow[t]{2}{*}{0.124} \\
\hline No & 8 & $(25.0)$ & 15 & (42.9) & \\
\hline \multicolumn{6}{|c|}{ Time required to control seizure (hour) } \\
\hline$<12$ & 10 & $(31.3)$ & 13 & $(37.1)$ & \multirow{5}{*}{0.931} \\
\hline$>1224$ & 14 & $(43.8)$ & 12 & $(34.3)$ & \\
\hline$>2436$ & 4 & $(12.5)$ & 5 & $(14.3)$ & \\
\hline$>3648$ & 1 & $(3.1)$ & 2 & $(5.7)$ & \\
\hline$>48$ & 3 & $(9.4)$ & 3 & $(8.6)$ & \\
\hline Group A & \multirow{2}{*}{\multicolumn{4}{|c|}{$\begin{array}{l}\text { Inj. Lidocaine } \\
\text { Inj. Phenytoin }\end{array}$}} & \\
\hline Group B & & & & & \\
\hline \multicolumn{6}{|c|}{$\begin{array}{c}\text { Table IV } \\
\text { Complicationctand }\end{array}$} \\
\hline \multicolumn{6}{|c|}{ Complications and outcome of neonates during hospital stay } \\
\hline \multirow[t]{2}{*}{ Parameters } & \multicolumn{2}{|c|}{ Group A $(n=32)$} & \multicolumn{2}{|c|}{ Group B $(\mathrm{n}=35)$} & $\mathrm{P}$ value $\left(\div^{2}\right.$ test $)$ \\
\hline & No. & $(\%)$ & No. & $(\%)$ & \\
\hline \multicolumn{6}{|l|}{ Adverse effect } \\
\hline Yes & 4 & $(12.5)$ & 10 & $(28.6)$ & 0.106 \\
\hline No & 28 & $(87.5)$ & 25 & (71.4) & \\
\hline \multicolumn{6}{|l|}{ Type of adverse effect } \\
\hline Apnea & 1 & $(25.0)$ & 3 & $(30.0)$ & \\
\hline Bradycardia & 2 & $(50.0)$ & 2 & $(20.0)$ & \\
\hline Drowsiness and lethargy & 1 & $(25.0)$ & 5 & $(50.0)$ & \\
\hline \multicolumn{6}{|l|}{ Treatment outcome } \\
\hline Discharged with advice & 25 & $(78.1)$ & 23 & $(65.7)$ & \\
\hline Left against medical advice & e 3 & $(9.4)$ & 5 & $(14.3)$ & 0.530 \\
\hline Expired & 4 & $(12.5)$ & 7 & $(20.0)$ & \\
\hline \multicolumn{6}{|l|}{ Hospital stay (days) } \\
\hline$<5$ & 2 & (6.3) & 7 & $(20.0)$ & \\
\hline 57 & 11 & $(34.4)$ & 8 & $(22.9)$ & 0.352 \\
\hline $8-10$ & 16 & $(50.0)$ & 16 & $(45.7)$ & \\
\hline$>10$ & 3 & $(9.4)$ & 4 & (11.4) & \\
\hline
\end{tabular}

Group A : Inj. Lidocaine

Group B : Inj. Phenytoin

* = Significant at $\mathrm{P}<0.05$ 


\section{Discussion :}

Intractable neonatal seizure are common acute medical emergency in special care baby unit (SCABU). Seizure occurs more often during the neonatal period than at any other period of life. The present study was carried out to compare the efficacy of phenytoin with lidocaine in the management of intractable seizure in neonate. The two study groups in present study were almost similar with respect to their sex, birth, weight apgar scores, gestational age, mode of delivery, age on admission, types of seizures, age at onset of seizure.

The study demonstrated that seizure of $75 \%$ neonates was controlled with inj. Lidocaine and seizure of $57.1 \%$ neonates was controlled with Inj, phenytoin. In a Japanese retrospective, multicenter questionnaire study shows, Lidocaine was effective in $70 \%$ of neonates ${ }^{12}$. Rey et al ${ }^{7}$ achieved control of seizure in $85 \%$ of neonates. Malingre et al ${ }^{9}$ in their study shows lidocaine was effective in $76 \%$ of patients. Results of several small, noncontrolled studies indicate that lidocaine is an effective drug for treating neonatal convulsions not responding to traditional anticonvulsant therapy, with the response rate varying from $70 \%$ to $92 \% .4,5,7,8,12,13,14$ Hellstrom-Westas and associates ${ }^{8}$ showed in 1988 that lidocaine was effective in $92 \%$ of the patients non responding to phenobarbital and diazepam. Lidocaine was administered as an intravenous bolus followed by continuous infusion. No adverse effects were observed. Malingre and colleagues ${ }^{9}$ studied two groups of neonates during treatment of neonatal siezures with different lidocaine dosing regimeans to develop and optimal lidocaine infusion strategy. No adverse effects were reported in either group. In a Japanese retrospective, multicenter questionnaire study shows lidocaine was effective in five of seven $(70 \%)$ neonates who were younger than 1 week of age and had generalized seizures ${ }^{12}$. The patients were refractory to diazepm, phenobarbital, or phenytoin. Lidocain led to seizure termination in $63 \%$ of term infants when used as $2^{\text {nd }}$ line treatment for neonatal seizure without prior treatment with phenobarbital. On the other hand, Laurel et $\mathrm{al}^{5}$ study show the efficacy is only approximately
$50 \%$ of phenobarbital and phenytoin in neonatal seizure. Phenytoin was shown to only provide about a $10 \%$ to increase in seizure control when given following phenobarbital failure. ${ }^{5}$ Federico et al ${ }^{6}$ shows control seizures of $55 \%$ of neonates with Inj. Phenytoin. Seizure were controlled fewer than half of patients. ${ }^{15}$

In present study the total adverse effects were seen in $4(12.5 \%)$ and $10(28.6 \%)$ patients of lidocaine and phenytoin group respectively. Out of them apnea was seen in 1 patient, bradycardia in 2, drowsiness \& lethargy in 1 patients in lidocaine group. On the other hand in phenytoingroup found apnea in 3 patients, bradycardia in 2 patients, drowsiness \& lethargy in 5 patients. Hellostrom Westas ${ }^{16}$ found adverse effects (bradycardia) in 2 patients (out of 24) during treated by Inj. Lidocaine which leads to an immediate termination of the infusion. Lidocaine can be an active anti convulsant drug when other anticonvulsive therapy has failed. Lidocaineis considered to be effective only when convulsion are controlled for 24 hours. ${ }^{17}$ Routine blood measurements of lidocaine concentrations during anticonvulsive treatment in neonates seem to be of little clinical value. ${ }^{16}$ Lidocaine has a harrow therapeutic range and can induce seizure in high dose. ${ }^{17}$

Time required to control seizure is nearly similar in both groups. In lidocaine group $75 \%$ of patients responded within 24 hours. On the other hand $71 \%$ of patients responded in same duration in phenytoin group. Lidocaine is considered to be effective only when convulsion are controlled for 24 hours. ${ }^{17}$ Boylan et al 14 shows $60 \%$ of neonates responded to lidocaine after failure of phenobarbitone\& took more than 12 hours. Cessation of seizure activity 6 hours or longer is seen in $77 \%$ of patients and was considered a good response. ${ }^{4}$ HellostromWestas shows the $83 \%$ of patients responds to lidocaine within 12 hours $^{8}$. Lidocaine led to seizure termination of neonatal seizure in $63 \%$ of term infants when administrated as second line treatment for neonatal seizure within 24 hours. ${ }^{18}$

In the present study, length of hospital stay is less in phenytoin group ( 7 patients in 5 days) 
in comparable to lidocaine group (2 in 5 days). But this findings could not signify efficacy of the drugs. As death (total 20\%), left against medical advice $(14.3 \%)$ is more in phenytoin group than in lidocaine group (death $12.5 \%$, left against medical advice $9.4 \%$ ).

In summary for controlling intractable neonatal seizures Inj. Lidocaine group showed more efficacious than Inj. phenytoin group and causing less adverse effects. Though it is not statistically significant.

\section{Conclusion:}

Inj. Lidocaine is similar to Inj. Phenytoin in controlling intractable neonatal seizure. But large sample, multi centre randomized trial needed to validate the effect of lidocaine in controlling intractable seizure.

\section{References:}

1. Gomella TL, Cunnighum MD. Eyal FG. Lange Neonatology. $6^{\text {th }}$ edition P857859.

2. Mizrahi ME. Neonatal Seizures. In: Swaiman FK, A shawl S, Ferriero MD, editors. Paediatric Neurology: Principles \& Practice. Philadelphia: Mosby, Elsevier; 2006. P. 257-78.

3. Volpe J. Neonatal seizures. In: Neurology of the newborn. $5^{\text {th }}$ ed. Philadelphia, Pa: WB Saunders Co; 2008: 203-244

4. Shany E, Benzaqen O, Watemberg N. Comparison of continuous drip of midazolam or lidocaine in the treatment of intractable neonatal seizure. Journal of Child Neurology. March 2007; 22 (3): 255-259.

5. Slaughter LA, Patel AD, Slaughter JL. Pharmacological treatment of neonatal seizure: A systematic review. Journal of Child Neurology. 2013; 28 (3): 351-364.

6. Sicca F, Contaldo A, Rey E, Dulac O. Phenytoin administration in the newborn and infant. Journal of the Japanese Society of Child Neurology. Brain and Development. 2000; 22: P 35-40.

7. Rey E, Radvanvi-Bouvet MF, Bodiou C, Richard M.O., Torricelli A., et al. Intravenous lidocaine in the treatment of convulsions in the neonatal period: monitoring plasma levels. Ther Drug Monit. 1990;12:316-320.
8. Hell strom-Westas L, Westgren U, Rosen I, Svenningsen NW. Lidocaine for treatment of severe seizures in newborn infants. I. Clinical effects and cerebral electrical activity monitoring. ActaPaediatr Scand. 1988; 77:79-84.

9. Malingre MM, Van Rooij LGM, Rademaker CMA, Toet MC, De Vries LS, et al. Development of an optimal lidocaine infusion strategy for neonatal seizures. European Journal of Pediatrics. 2006; 165:598-604.

10. Van Rooij LGM, Toet MC, Rademaker KM, Groenendoal F, De, Vries. LS. Arrythmias in neonates receiving lidocaine as anticonvulsive treatment. European Journal of Pediatrics. November 2004, Vol 163, p 637-641.

11. Lenmen L J, Klassen M, Duiser B. Intravenous lidocaine in the treatment of convulsions. JAMA, 1978; 239: 2025.

12. Hattori $\mathrm{H}$, Yamano $\mathrm{T}$, Yamanoto $\mathrm{H}$, Aihara $\mathrm{M}$, Yamanouch H, et a. Effectiveness of lidocaine infusion for status epilepticus in childhood: A retrospective multi-institution study in Japan. Journal of the Japanese Society of Child Neourology. Brain \& Development 2008; 32: 504-512.

13. Booth D, Evans DJ. Anticonvulsants for neonates with seizures. Cochrane Database Syst Rev. 2004; 4: CD004218.

14. Boylan GB, Rennie JM, Chorley G, Pressler RM, Fox G.F., et al. Second-line anticonvulsant treatment of neonatal seizures: a video- EEG monitoring study. Neurology. 2004;62:486-488.

15. Painter MJ, Scher MS, Stein AD, Armatti S, Wang $Z$, et al. Phenobarbital compared with phenytoin for the treatment of neonatal seizures. NEngl $\mathrm{J}$ Med. 1999;341:485-489.

16. Hellstrom-Westas L, Westgren U, Rosen I, Svenningsen NW. Lidocaine for treatment of severe seizures in newborn infants. II. Blood concentrations of lidocaine and metabolites during intravenous infusion. ActaPaediatr. 1992; 81: 35-39.

17. Yamamoto $\mathrm{H}$, Aihara M, Niijima S, Yamanouchi $\mathrm{H}$. Treatments with midazolam and lidocaine for status epilepticus in nconates. Journal of the Japanese Society of Child Neourology. Brain and Development. 2007; 29:559-564.

18. Lunqgvist M, Agren J, Hellstrom-westas L, Flink R, Wickstrom R. Efficacy and safety of Lidocain in the Treatment of neonatal seizure. Acta Pacdiatrica. 2013; 102: 863-867. 